\title{
The Effect of Teachers' Memory-Relevant Language on Children's Strategy Use and Knowledge
}

\author{
Jennie Grammer \\ University of Michigan
}

\author{
Jennifer L. Coffman and Peter Ornstein \\ The University of North Carolina at Chapel Hill
}

\begin{abstract}
Building on longitudinal findings of linkages between aspects of teachers' language during instruction and children's use of mnemonic strategies, this investigation was designed to examine experimentally the impact of instruction on memory development. First and second graders $\left(N=54, M_{\text {age }}=7\right.$ years) were randomly assigned to a science unit that varied only in teachers' use of memory-relevant language. Pretest, posttest, and 1-month follow-up assessments revealed that although all participating children learned new information as a result of instruction, those exposed to memory rich teaching exhibited greater levels of strategic knowledge and engaged in more sophisticated strategy use in a memory task involving instructional content than did students exposed to low memory instruction. The findings provide support for a causal linkage between teachers' language and children's strategic efforts.
\end{abstract}

A rich literature characterizes the development of children's skills in the deliberate deployment of strategies for remembering (Ornstein, Haden, \& San Souci, 2010; Schneider \& Pressley, 1997). For example, mnemonic techniques such as rehearsal and meaning-based sorting become increasingly complex and effective over the course of the elementary school years (Ornstein, Baker-Ward, \& Naus, 1988). Nonetheless, even though there has been a great deal of interest in children's memory, surprisingly little is known about the factors that serve to bring about developmental changes in remembering (Ornstein \& Haden, 2001). A number of lines of work, however, point to the importance of experience in formal school settings for the emergence and consolidation of children's mnemonic skills (Morrison, Smith, \& Dow-Ehrensberger, 1995; Rogoff, 1981). Moreover, additional evidence suggests

This research was supported in part by grants from the National Science Foundation (BCS-0217206 and 0519153) to the third author, as well as a Predoctoral Fellowship provided by the National Institute of Child Health and Human Development (T32-HD07376) through the Center for Developmental Science, UNC- $\mathrm{CH}$, to the first author. We are grateful to the participating families, after-school directors, and students for supporting this project. In addition, we wish to thank Maria Finnegan, Ann Kelly, and Adrienne Smith for professional assistance, and Allison Mugno, Deborah Zimmerman, Amy Hedrick, Kathryn Howlett, Hillary Langley, Sheena Berry, Ben Cox, Hannah Kirby, Elizabeth Martin, Zach Martin, Lauren Martin, Cherelle McKnight, Rachel Reyes, and Lauren Upton for their assistance with data collection and coding.

Correspondence concerning this article should be addressed to Jennie Grammer, University of Michigan, Department of Psychology, 530 Church St., Ann Arbor, MI 48104-1043. Electronic mail may be sent to grammer@umich.edu. that aspects of the language used naturally by teachers during the course of instruction-and more specifically, teacher's mnemonic orientation that includes the provision of metacognitive information-may be important for the development of deliberate strategies for remembering (Coffman, Ornstein, McCall, \& Curran, 2008). Accordingly, this study was designed to examine experimentally the impact of this language on children's developing use of mnemonic techniques.

The experiment reported here is grounded in several disparate literatures that when integrated lead to the plausible inference that teachers' use of memory-relevant language may influence the development of young children's mnemonic skills. The importance of formal schooling for the development of memory strategies was first suggested by a number of important comparative-cultural research programs that included contrasts between groups of same-aged children who did or did not have significant experience in Western-style schools. More specifically, studies carried out in Liberia (Sharp, Cole, \& Lave, 1979), Mexico (see Rogoff, 1981, for a review), and Morocco (Wagner, 1978) revealed that children who had the opportunity to attend school were more skilled in the use of deliberate memory strategies than were their peers who did not have this experience in school. Although these important

(C) 2013 The Authors

Child Development (c) 2013 Society for Research in Child Development, Inc. All rights reserved. 0009-3920/2013/8406-0014

DOI: $10.1111 /$ cdev. 12100 
studies implicate the school setting as being particularly important for the development of skilled remembering, they do not inform our understanding of the specific grades in school that may be associated with the development of memory. However, research that contrasts the performance of children who fall on either side of the mandated cutoff date for school entry (Morrison et al., 1995) identifies the first-grade classroom as an important developmental context for early memory skills. Morrison et al. (1995) observed that "young first graders" (i.e., those children who just "made" the cutoff for first-grade) evidenced greater growth in remembering over the school year than did "old kindergartners" (i.e., those children who just "missed" the cutoff).

Notwithstanding the potential importance of the first-grade classroom as a context for the emergence and refinement of deliberate strategies for remembering, just what about the classroom setting is important? One thing is clear from the few studies that have involved detailed observation in elementary school classrooms: Teachers do not generally provide explicit instruction to their students in the use of mnemonic techniques. Indeed, Moely et al. (1992; see also Coffman et al., 2008) reported that explicit strategy instruction in the classroom is a low-frequency event, but that when it does take place, children's performance seems to be facilitated. Nonetheless, given that such instruction is rarely observed, some other feature of the classroom must play a role in supporting the emergence and refinement of deliberate memory strategies, and it seems possible that some stylistic feature of teachers' language during instruction may be implicated. This perspective is consistent with the wealth of evidence demonstrating that the nature of the social interaction as revealed in adult-child conversations about both previously experienced (e.g., Reese, Haden, \& Fivush, 1993) and ongoing events (Haden, Ornstein, Eckerman, \& Didow, 2001) may be linked to preschoolers' abilities to provide reports of these experiences. By extension, it seems likely that the nature of the language used by teachers during instruction would also be associated with children's deliberate use of mnemonic strategies.

In this regard, what can be said about the language that teachers use during instruction in elementary school classrooms? Given that instruction in memory strategies is a rare event in the classroom, Coffman et al. (2008) focused their efforts on examining other aspects of the language that firstgrade teachers included in their teaching. More specifically, in their longitudinal study Coffman et al. observed the extent to which teachers used memory-relevant and metacognitive language during their language arts and mathematics lessons. In doing so, they noted that teachers rarely reference memory directly during instruction, but that examples of "memory talk" abound and seem to reflect in-the-classroom instantiations of lessons learned from the memory literature, especially research on metacognitive awareness (e.g., Ornstein, Haden, \& Elischberger, 2006) and depth of processing (e.g., Craik \& Lockhart, 1972; Ornstein \& Corsale, 1979). Indeed, teachers often encourage their students to apply what they already know in the service of the goals of understanding and remembering, and they also foster activities (e.g., categorization, links to previous experiences) that support memory by increasing the depth to which information is processed. For example, a teacher may begin a lesson by referencing what the class had learned the day before, or could ask the children to, "Make groups of words that have 'long $a$ ' versus 'short a' sounds." In the context of instruction in mathematics and language arts, teachers frequently request metacognitive information and make suggestions for strategies that children might use in the service of understanding and learning. To illustrate, a teacher may ask, "What are some strategies that you could use to solve this problem?" or may suggest, "If you come to a word you don't know, you can read the rest of the sentence to see what could make sense there and it may help you figure it out."

In addition to documenting "memory talk" in the classroom, Coffman et al. (2008) noted that there was considerable variability across teachers in the amount of such language and that as a result it was possible to construct a measure of "mnemonic style" that reflected the degree to which references to memory and metacognition permeated the classroom, even when teachers were not providing direct instruction in the use of strategies for remembering. In conjunction with their extensive in-class observations, Coffman et al. assessed various aspects of the children's memory performance and they found that by the spring of the first-grade, children who had been taught by high-mnemonic teachers exhibited more sophisticated strategy use than their peers in classes taught by low-mnemonic teachers. Importantly, these differences in performance as a function of their first-grade teachers' mnemonic style were observed in the children's use of strategies during the second grade, even though they were taught by different teachers (Ornstein, 
Coffman, Grammer, San Souci, \& McCall, 2010). Similarly, there were long-lasting associations between the mnemonic style of first-grade teachers and children's strategic sorting and use of academic study skills in the fourth grade (Ornstein, Grammer, \& Coffman, 2010). Thus, although children's memory strategy use improves greatly across the early grades in general, there may be something unique about the first-grade classroom context that is important for the development of these skills.

Extending their exploration of linkages between teachers' mnemonic orientation and children's strategies for remembering, Ornstein, Coffman, and their colleagues have also examined relations between instructional style and student achievement in mathematics. Observing that lessons in mathematics were, on average, mnemonically richer than were those in language arts, Grammer, Coffman, Sydney, and Ornstein (2013) focused on the extent to which the teachers' mnemonic style while teaching mathematics might be linked to their students' mathematics achievement. They found that even though the majority of the children made gains in mathematics achievement across the second grade, the magnitude of the growth varied as a function of their teachers' mnemonic style in mathematics instruction. Indeed, on both the calculation and math fluency subscales on the Woodcock-Johnson Tests of Academic Achievement, children whose second-grade teachers were classified as high mnemonic in mathematics showed significantly more improvement than children whose teachers were classified as low mnemonic in mathematics. Although these linkages between teachers' mnemonic style and children's academic achievement were not initially the focus of Coffman, Ornstein, and their colleagues, their findings are nonetheless consistent with demonstrations that teachers' instructional practices-including the use of metacognitively rich language - are important for children's progress in language arts and mathematics (e.g., Crosnoe et al., 2010; Pressley \& Hilden, 2006).

Given the potential importance of teachers' mnemonic orientation during classroom instruction for the development of children's memory strategies and academic skills, the study presented here was designed to determine if the observed correlational linkages could be brought under experimental control. To carry out this experiment, children who were attending after-school programs were given the opportunity to participate in 2-week units of study on Things That Move. The focus of the units was on simple physics and engineering principles that are involved in the building - with Lego mate- rials — of "sturdy structures" and vehicles. As such, the children were exposed to simple machines, wheels-and-axles, gears, and so on, and had many opportunities to "work like engineers." The instructional units were taught by licensed elementary school teachers who first mastered the material and then were trained to present it to different groups of participants in either a high or a low mnemonic fashion. Thus, although the activities and material covered in the lessons were the same for all participants, the language used by the teachers to present the content differed and was modeled on the two contrasting mnemonic styles documented by Coffman et al. (2008) as occurring naturally in firstgrade instruction.

Although all students were expected to learn much of the material presented in the Things That Move unit-given that the teachers were licensed professionals and the curriculum was designed to be "hands on" and engaging - it was hypothesized that the children exposed to a high mnemonic style of instruction would evidence greater learning and skill in the use of strategies. This prediction was based not only on the correlational evidence reported by Coffman et al. (2008), but also on research from the memory development literature, including studies illustrating the key role of metacognitive understanding in the deployment of strategies (e.g., Grammer, Purtell, Coffman, \& Ornstein, 2011; Ornstein et al., 2006; Schlagmüller \& Schneider, 2002). Moreover, to explore the hypothesized impact of instructional style on children's performance, a battery of tasks was used to (a) assess the knowledge gained (including both engineering facts and strategies for solving problems) as a result of exposure to the Things That Move unit and (b) determine the extent to which sorting in preparation for remembering would be influenced by prior knowledge (as in taxonomic relations) or newly acquired understanding (as in the knowledge gained from the instructional unit).

\section{Method \\ Experimental Design and Participants}

To draw connections between teachers' mnemonic style and children's use of memory strategies, the participating children were assigned to one of two contrasting instructional conditions that were modeled on the high and low mnemonic styles identified by Coffman et al. (2008): the memory rich versus the low memory groups, respectively. All children received the same unit on Things That Move that was 
taught by one of three licensed elementary school teachers who had previously received intensive instruction in the subject matter. These teachers, however, also received instruction in teaching according to scripts based on the naturally occurring high and low mnemonic styles, and each teacher taught two 10-day units. Thus, each teacher instructed two separate groups of students, with one group experiencing the unit in the memory rich condition and the other in the low memory condition. To assess the effects of exposure to memory rich versus low memory styles of instruction, the children were assessed prior to instruction, at the conclusion of the unit, and once again after an additional month.

The participants included 54 children, 25 boys and 29 girls, recruited from established after school programs in three elementary schools. At the beginning of the experiment, the group of children was 7 years 2 months of age, on average, and included an even number of first- and second-grade students. The diversity of the sample reflected the Southern suburban area from which the participants were drawn, with $57 \%$ of the families describing their ethnicity as European American, 15\% as African American, 11\% as Latino, $11 \%$ as Asian, and $6 \%$ as being mixed ethnicity. All but six of the families reported speaking English as their primary language in the home.

The children were assigned randomly to either the memory rich or low memory conditions. Of the participants, 28 children were enrolled in the memory rich instructional condition, whereas 26 were assigned to the low memory condition. Overall, the sample included approximately equal numbers of girls and boys, and the number of girls assigned to each condition reflected the composition of the sample $\left(N_{\text {memory rich }}=15\right.$ and $\left.N_{\text {low memory }}=14\right)$. Children across the two conditions were also similar with respect to ethnicity. Although equal numbers of first and second graders took part in the study, more first-grade children participated in the memory rich condition $\left(N_{\text {memory }}\right.$ rich $=15$ and $N_{\text {low memory }}=12$ ). However, $t$ tests revealed that the groups did not differ significantly in age at the beginning of the investigation $\left(M_{\text {memory rich }}=\right.$ 85.9 months and $M_{\text {low memory }}=88.0$ months).

\section{The Instructional Unit}

The instructional unit on Things That Move was presented in hour-long lessons that were held across 10 consecutive weekday afternoons in one of three after-school programs. Each of the lessons was organized around basic physics concepts, with specific emphasis placed on the utility of simple machines, the wheel and axle, and gears. Although the use of the materials resulted in engaging science lessons, the primary focus of this investigation was not on children's science learning, per se, but rather on using physical science as a vehicle for manipulating teachers' language during instruction so as to allow for an examination of fundamental questions regarding the causal connections between instruction and changes in children's knowledge and use of cognitive strategies.

In an effort to ensure that the content would be novel for the participating children, the topic was chosen after a review of the State-Mandated Course of Study for science education revealed that the basic concepts were not taught in public elementary schools in kindergarten, first, or second grade. The instructors utilized a variety of instructional activities, including those involving reading and mathematics. Lego Simple Machine sets were employed to facilitate children's exploration of the concepts, and the lessons included activities that integrated Lego building concepts with instruction in physical science. During each day of instruction, new information about topics such as simple machines, Lego terminology, building techniques, or gears was presented. Broadly, children participated in activities that included researching and learning about specific simple machine terminology, diagramming and writing about the machines that they wanted to build, examining gear ratios, and constructing machines involving wheels, axles, and gears to test out the concepts learned.

\section{Experimentally Manipulating Instruction}

The teachers were randomly selected to first teach either the memory rich unit that was modeled on the high mnemonic style of instruction, or the low memory unit, modeled on the low mnemonic style. During the course of the experiment, each of these three teachers taught two separate groups of 7-10 children, one in each instructional style. None of the teachers was provided with specific information regarding the basis for the manipulation.

To achieve differences in instructional style, scripted lessons were provided to the teachers for each unit. The lessons were designed to vary as a function of linguistic differences observed in the naturally occurring use of memory-relevant language in the lessons of high- and low-mnemonic teachers. More specifically, the contrasting scripts reflected differences between high- and low-mnemonic first-grade teachers observed by Coffman et al. (2008) in the extent to which they incorporated 
Table 1

Memory-Relevant Instructional Techniques

\begin{tabular}{|c|c|c|}
\hline & Definitions & Example \\
\hline \multicolumn{3}{|l|}{ Instructional techniques } \\
\hline $\begin{array}{l}\text { Strategy } \\
\text { suggestions }\end{array}$ & $\begin{array}{l}\text { Recommending that a child adopt a method or procedure for } \\
\text { remembering or processing information }\end{array}$ & $\begin{array}{l}\text { "If you are having trouble thinking of } \\
\text { ways to connect the wheel and axle, } \\
\text { you can look at the diagram } \\
\text { to help you." }\end{array}$ \\
\hline $\begin{array}{l}\text { Metacognitive } \\
\text { questions }\end{array}$ & $\begin{array}{l}\text { Requesting that a child provide a potential strategy, a utilized } \\
\text { strategy, or a rationale for a strategy he or she has indicated } \\
\text { using }\end{array}$ & $\begin{array}{l}\text { "How did you figure out which pieces } \\
\text { you would need to build a sturdy } \\
\text { structure? How did you know that } \\
\text { would work?" }\end{array}$ \\
\hline \multicolumn{3}{|c|}{ Instructional techniques co-occurring with deliberate memory demands } \\
\hline $\begin{array}{l}\text { Instructional } \\
\text { activities }\end{array}$ & $\begin{array}{l}\text { Requests for information from memory and the presentation of } \\
\text { instructional information by the teacher }\end{array}$ & $\begin{array}{l}\text { "Today we will be building our own } \\
\text { cars. Who knows the first step we take } \\
\text { when building a new structure?" }\end{array}$ \\
\hline $\begin{array}{l}\text { Cognitive structuring } \\
\text { activities }\end{array}$ & $\begin{array}{l}\text { Requests for information from memory and teacher instruction } \\
\text { that could impact the encoding and retrieval of information, } \\
\text { such as focusing attention or organizing material }\end{array}$ & $\begin{array}{l}\text { "All of these modes of transportation } \\
\text { have wheels. What is another vehicle } \\
\text { that you have seen around town that } \\
\text { also has wheels?" }\end{array}$ \\
\hline $\begin{array}{l}\text { Metacognitive } \\
\text { information }\end{array}$ & $\begin{array}{l}\text { Requests for information from memory and the provision or } \\
\text { solicitation of metacognitive information }\end{array}$ & $\begin{array}{l}\text { "What kind of gear is this? What clue } \\
\text { did you use to help you figure that } \\
\text { out?" }\end{array}$ \\
\hline
\end{tabular}

five components of mnemonic style into their whole-group lessons in mathematics and language arts: strategy suggestions, metacognitive questions, as well as the co-occurrence of deliberate memory demands with (a) instructional activities, (b) cognitive structuring activities, or (c) metacognitive information. These five components of mnemonic style thus provided the basis for the instructional style manipulation of this experiment and are illustrated in Table 1 in the context of the Things That Move curriculum.

As can be seen in Table 1, memory rich instruction was characterized by scripted lessons that included more frequent use of strategy suggestions and posed greater numbers of metacognitive questions than did the low memory lessons. In addition, in the memory rich condition, the instructor more regularly requested that the children remember information such as facts, events, or procedures, in conjunction with other routine activities thought to support children's remembering. These included instructional activities (e.g., book reading and providing general information), cognitive structuring activities (e.g., identifying features and categorizing information) or the provision or solicitation of metacognitive information. Examples and definitions of each of the instructional elements that were used more frequently in the memory rich instructional condition than the low memory condition can be seen in Table 1.

To help ensure instructor fidelity to both content and instructional style, a second experimenter was present to observe the presentation at each of the lessons. The instructors were provided with daily feedback regarding both their teaching of the content and their use of appropriate language during instruction. In addition, all instructional activities were filmed for subsequent coding and analyses.

\section{Measures}

\section{Child-Level Assessments}

Individual child-level assessments - of memory strategy use and knowledge of the basic concepts being taught-were carried out at pretest (prior to instruction), posttest (within 1-3 days after the completion of the unit), and 1 month later at a long-term follow-up. Each of these assessments was conducted one-on-one with the child by a trained experimenter and lasted 40-45 min. The assessment battery included measures of content-specific knowledge and strategy use, deliberate strategy use with familiar materials, and memory capacity. In addition, to measure children's receptive vocabulary, the 
Peabody Picture Vocabulary Test-Revised (PPVTIV; Dunn \& Dunn, 2007) was administered at the final assessment. All children were seen at each assessment, and equipment failure and children's noncompliance led to the loss of only a few measures (range $=0-2$ ) per assessment point.

Measures of knowledge. Facts. At each time point, the children's knowledge of the content covered in the instructional unit was assessed with a multiple choice and fill-in-the-blank questions that were read aloud to each child. Specifically the children were asked to provide definitions, correctly identify examples, and generate labels for questions involving simple machines, gears and Legos. The questions were the same at each assessment. A total of 26 points could be earned for answering these questions correctly, and each response was scored as being correct or incorrect.

Strategies. In addition to questions that assessed the children's factual understanding of the content presented, their strategic knowledge was also gauged using eight free-answer questions at the pretest, posttest, and 1-month follow-up. In addition to being asked more generally about their Lego building strategies, the children were also presented with scenarios that could occur while building structures with the Legos and for each one were asked to describe the strategies that they might use to solve a particular Lego building challenge. At each assessment, the children were presented with the same scenarios. Responses to the open-ended questions were transcribed, and the number of correct, unique responses to each question was tallied.

Measures of deliberate memory strategies. Contentspecific sort recall task. Modeled after Bjorklund, Ornstein, and Haig's (1977) sort recall procedure, this task was designed to assess children's use of spontaneous semantic organization when presented with items related to the content that was presented during the instructional unit. Because the participants would not be familiar with these content-based items and their interitem connections at the initial assessment point, it was possible to explore the extent to which the children imposed their own organization on the items. Moreover, at the subsequent assessments, the children's sorting patterns could be examined in relation to their newly acquired knowledge of the content, as well as their understanding of interitem associations.

At each assessment point, the children were presented with one of two counterbalanced sets of 15 cards. Each card had an individual photograph of a Lego piece, including plates, beams, gears, wheels, axles, and bushings. At the beginning of the task, the participants were asked to label each picture, and if a child could not identify an image, the experimenter provided the correct label. The experimenter then asked each child to form groups that he or she thought would facilitate remembering, using the cards and a special sorting board. The children were instructed further to make as few as two or as many as five groups with the cards. Each child was given 3 min following presentation of the pictures to sort them into groups and to "work to remember." During the study period, the experimenter made notes that described the sorting patterns of the children. Recall of the items was assessed immediately following the study period. In addition, after the trial, the experimenter asked the child to explain the groups and to nominate strategies that were used while studying the items.

Two independent raters evaluated the children's use of an organizational sorting strategy. Each sorted group was initially scored to reflect the extent to which the cards were placed randomly or on the basis of visual aspects of the Lego pieces (e.g., color or shape), functional relation among the items, or semantic associations among the pieces. Ratings for the overall sorting patterns of each child were then made based on the records of the sorted groups and the children's self-reported rationales. Scores ranged from 0 (sorting was done at random), to 2 (at least one of the groups was sorted on the basis of semantic or functional linkages), to 4 (the majority of the groups were organized by strong semantic of functional associations). After the raters independently scored a child's sorting pattern, the two coded files were compared and any discrepancies were later resolved through discussion or scoring by a third coder.

Free recall with organizational training task. At each administration of the free recall with organizational training task (Moely et al., 1992), the children were presented with 16 cards with line drawings of items that were drawn from four conceptual categories. At the pretest, each child was given an initial baseline trial that was followed immediately by a second trial, during which strategy training in meaningbased sorting and clustering in recall was provided. At the same assessment, after a 15-min delay, each child was also given an initial generalization trial. Moreover, at the posttest and 1-month follow-up, the children were presented with a single noninstructed generalization trial.

On the baseline trial at pretest, the picture cards were presented in a quasi-random order, such that categorically related items were not displayed alongside each other, and the children were told to 
do whatever they could to remember the pictures. On the subsequent training trial, the participants were instructed in the use of categorization during study (sorting) and recall (clustering) as aids to remembering. To assess the children's use of sorting and clustering strategies in the absence of specific instructions to do so, a generalization trial was administered 15 min later with a new set of cards. Subsequent assessments of long-term generalization of the trained organizational strategy were obtained at the posttest and 1-month follow-up. Throughout the administration of the task, the experimenter recorded the children's sorting patterns, the number of items recalled, and the order in which the pictures were reported. With this information, a standard index of categorical grouping, the adjusted ratio of clustering (ARC) score (Roenker, Thompson, \& Brown, 1971), was calculated to characterize the children's sorting during the study period. The ARC scores could range from -1 (below chance organization), to 0 (chance), to 1 (complete categorization). In addition, the children's recall of the items at each administration of the task was assessed. Two coders independently scored all records, with any discrepancies being resolved through examination of the original videotapes.

Measures of memory capacity and vocabulary. Digit span. Following standardized assessment procedures (McCarthy, 1972), two forward and two backward span trials were administered during the posttest assessment to provide measures of the children's short-term and working memory. On each forward span trial, strings of numbers of increasing length were presented, with the child's task being to repeat the numbers in sequence. On each backward span trial, strings of numbers were presented, and the children were asked to repeat the numbers in the opposite order from which they were read. A child's forward and backward span was measured as the length of the longest string of digits that could be produced without error. The experimenter documented children's performance on this measure during the assessment. Two coders subsequently independently scored all records, with any discrepancies being resolved through examination of the original coding sheet.

PPVT. To measure receptive vocabulary, the PPVT-IV (Dunn \& Dunn, 2007) was administered at the final 1-month assessment. Using standardized assessment procedures, the children were shown a series of displays, each with four pictures, and for each display asked which picture best described a given word. For each child, a standardized score was calculated.

\section{Results}

To examine the possible impact of teachers' mnemonic style on the children's performance, it is first necessary to demonstrate that the instructors were able to adhere to the memory rich and low memory instructional styles when they were teaching the Things That Move unit. Accordingly, in the sections that follow, assessments of the teachers' fidelity to instructional condition are considered first and then followed by a treatment of various measures of the children's performance, as a function of assignment to memory rich versus low memory conditions.

\section{Instructional Fidelity}

The teachers' fidelity to instructional condition was assessed by a trained independent observer who watched a subset of three randomly selected whole-group lessons drawn from each of the six separate instructional units ( 3 teachers $\times 2$ modes of instruction). This observer was an experienced and reliable coder who had made extensive use of the coding system in the previous longitudinal work (Coffman et al., 2008) that set the stage for this study, but who was not involved in the experimental manipulation. One third of each teacher's lessons were categorized as either low memory or memory rich by the observer, who was blind to the instructional condition. In order to fully characterize the nature of instruction to which the children in each condition were exposed, the initial fidelity check was augmented by coding of the lessons in terms of the five components of mnemonic orientation used by Coffman et al. (2008).

In the initial characterization of the instruction by the observer who was blind to the experimental manipulation, $100 \%$ of the 18 whole-group lessons viewed were identified correctly as being drawn from either the memory rich or low memory instructional condition, suggesting a high level of fidelity to experimental condition. Further coding of these 18 lessons documented clear differences in the nature of instruction that the children experienced across the two conditions and suggested that memory rich and low memory teaching styles corresponded to the high- and low-mnemonic modes of instruction that have been documented in firstgrade classrooms (Coffman et al., 2008). The teachers' use of memory-relevant language in the two instructional conditions is presented in the first and second panels of Table 2. As can be seen, the percentage of intervals containing the component codes that were targeted in the memory rich condition 
Table 2

Mean Percent Occurrences of Memory-Relevant Instructional Techniques in the Experimental Investigation and Grade 1 (Grade 1 Values Drawn From Coffman et al., 2008)

\begin{tabular}{|c|c|c|c|c|}
\hline & \multicolumn{2}{|c|}{$\begin{array}{c}\text { Experimental } \\
\text { instruction (\%) }\end{array}$} & \multicolumn{2}{|c|}{ Grade $1(\%)$} \\
\hline & $\begin{array}{l}\text { Memory } \\
\text { rich }\end{array}$ & $\begin{array}{l}\text { Low } \\
\text { memory }\end{array}$ & $\begin{array}{c}\text { High } \\
\text { mnemonic }\end{array}$ & $\begin{array}{l}\text { Low } \\
\text { mnemonic }\end{array}$ \\
\hline \multicolumn{5}{|c|}{ Instructional techniques } \\
\hline $\begin{array}{l}\text { Strategy } \\
\text { suggestions }\end{array}$ & 12.8 & 1.9 & 7.3 & 2.5 \\
\hline $\begin{array}{l}\text { Metacognitive } \\
\text { questions }\end{array}$ & 18.7 & 2.4 & 6.9 & 2.9 \\
\hline \multicolumn{5}{|c|}{ The co-occurrence of deliberate memory demands and } \\
\hline $\begin{array}{l}\text { Instructional } \\
\text { activities }\end{array}$ & 36.7 & 36.3 & 42.1 & 33.2 \\
\hline $\begin{array}{l}\text { Cognitive } \\
\text { structuring } \\
\text { activities }\end{array}$ & 25.7 & 19.2 & 25.4 & 21.5 \\
\hline $\begin{array}{l}\text { Metacognitive } \\
\text { information }\end{array}$ & 14.1 & 2.1 & 8.9 & 2.8 \\
\hline
\end{tabular}

Note. Percent occurrence of individual teacher behaviors derived from coding of 30-s intervals of instruction.

(strategy suggestions, metacognitive questions, and the co-occurrence of deliberate memory demands with instructional activities, cognitive structuring activities, and metacognitive information) differed substantially across the two instructional groups. In addition, the percent occurrence of these same codes in the longitudinal work on which the present experimental manipulation was based (Coffman et al., 2008) is presented in the third and fourth panels of Table 2. Inspection of this table reveals that the teachers were able to provide instruction in Things That Move in two contrasting styles that mapped on very well to the differences in instructional practices that are observed naturalistically in Grade 1 classrooms.

\section{Children's Performance as a Function of Teachers' Instructional Style}

With this demonstration that the teachers could readily adopt the two instructional styles, it is possible to determine the impact of the memory rich and low memory modes of teaching on the children's acquired knowledge and strategy use. However, before directly addressing these aspects of the children's performance, it is important to examine the extent to which the two instructional groups may have differed at the outset of the study in
Table 3

Children's Basic Memory and Language Skills

\begin{tabular}{lccc}
\hline & $M$ & $S D$ & Range \\
\hline $\begin{array}{l}\text { Short-term memory span } \\
\text { Memory rich }\end{array}$ & 4.96 & 0.62 & $4-7$ \\
$\quad$ Low memory & 5.54 & 0.96 & $4-7$ \\
Working memory span & & & \\
$\quad$ Memory rich & 3.21 & 0.62 & $2-4$ \\
$\quad$ Low memory & 3.77 & 0.91 & $2-6$ \\
PPVT standard scores & & & \\
$\quad$ Memory rich & 118.85 & 12.24 & $90-135$ \\
$\quad$ Low memory & 114.12 & 14.40 & $88-140$ \\
\hline
\end{tabular}

Note. PPVT $=$ Peabody Picture Vocabulary Test.

terms of age, memory capacity, and receptive vocabulary skills.

\section{Preliminary Analyses}

The children's short-term and working memory performance (as assessed using longest forward and backward spans, respectively), as well as their PPVT standard scores, are displayed as a function of instructional condition in Table 3. As can be seen, even though the participants were assigned randomly to the two groups, the children in the memory rich condition on average had significantly lower short-term memory scores than did their peers in the low memory group, $t(52)=-2.55, p<.01$. In contrast, the groups did not differ in terms of working memory performance. Given the differences between the two groups in the children's short-term memory, digit span performance was included as a covariate in each of the initial analyses of variance (ANOVAs) that was carried out on the knowledge and strategy use measures. However, inclusion of the short-term memory scores as covariates did not impact the results, and as such, short-term memory performance was not included in the ANOVAs reported next. Because of the repeated measures structure of the data, a Greenhouse-Geisser correction was employed in all analyses.

\section{Knowledge of Things That Move}

As can be seen in the top panel of Figure 1, the children in both groups knew very few facts about Things That Move when assessed on the pretest prior to instruction. Inspection of the figure also indicates that the two groups of children responded well to instruction, $F(2,104)=171.89, p<.01$, with their scores improving substantially over the course of the unit, as can be seen in their command of 

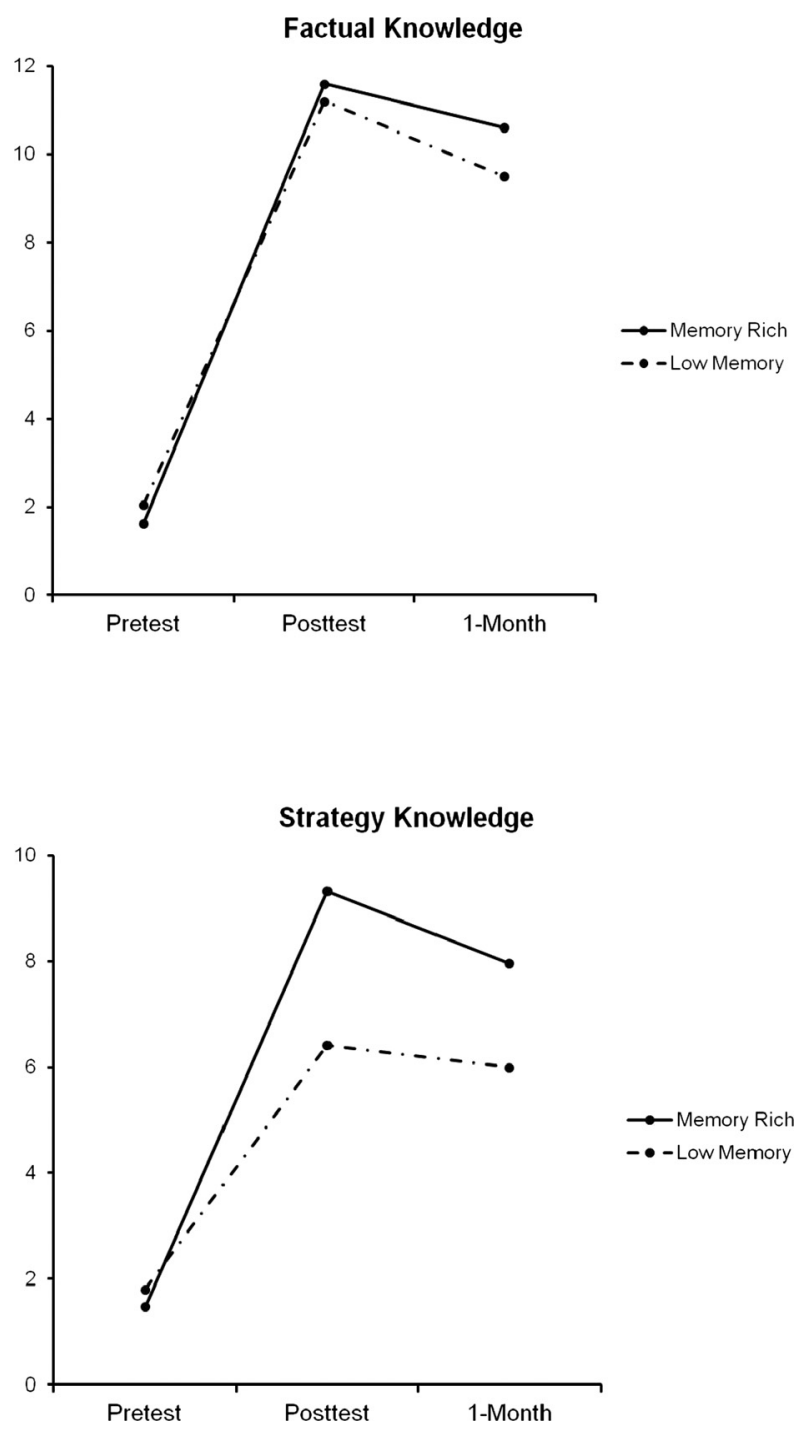

Figure 1. Children's knowledge of facts and strategies as a function of teacher instructional style and pretest, posttest, and 1month follow-up.

more than 11 facts at the posttest, with a slight drop after 1 month. Indeed, as is depicted in Figure 1, the two groups exhibited similar levels of factual knowledge at both of these postinstruction assessments, with neither the instructional conduction effect nor the interaction between instructional condition and time being significant.

In contrast, a different pattern is revealed in the bottom panel of Figure 1 in which children's knowledge of strategies for solving problems with the Things That Move materials is displayed. At the pretest, strategic understanding was both limited and comparable across the two groups of children, as was the case with their factual knowledge, but by the posttest assessment, there were clear differences in the children's knowledge of strategies. Both groups acquired a considerable number of strategies during the course of instruction, $F(2$, $102)=175.18, p<.01$, but the strategic knowledge of the children in the memory rich condition was greater than that of their peers in the low memory condition at both the posttest and the delayed assessment after 1 month, as reflected in a significant interaction between instructional condition and time, $F(2,102)=10.68, p<.01$. Further exploration of the data revealed that the group differences were significant at both the posttest, $t(52)=3.05, p<.01$, and the 1-month assessment, $t(52)=2.45 p<.05$, but not at the pretest.

\section{Deliberate Memory Skills}

It is one thing to acquire skills in the use of strategies for solving problems that arise in the course of building structures with the Things That Move materials, and it is another to use that strategic knowledge in the service of memory goals. To evaluate the children's skills in using what they had learned during the instructional unit, their meaning-based sorting was examined in the content-specific sort recall task (modeled after Bjorklund et al., 1977) in which they were instructed to form groups that would help them remember. More specifically, their deliberate use of specific interitem associations that were acquired during the Things That Move unit was scored according to a semantic coding scheme adapted from that used by Bjorklund et al. (1977), thus permitting a measure of the extent to which strategic knowledge was applied deliberately to support remembering.

As can be seen in the top panel of Figure 2, the instructional manipulation clearly influenced the children's strategic use of the concepts to which they were exposed in the Things That Move unit. Inspection of the figure indicates that the two groups were equivalent in strategic sorting at the pretest and that both evidenced growth across the instructional unit, $F(2,102)=10.16, p<.01$. The two instructional conditions differed, however, in their strategic sorting over time, and clear group differences were apparent after instruction, as reflected in a significant interaction between instructional condition and time, $F(2,102)=3.35, p=.04$. Further analyses revealed that children in the two instructional conditions differed in the sophistication of sorting at the posttest assessment, with those who had participated in the memory rich instructional unit demonstrating more meaning-based sorting than those in 


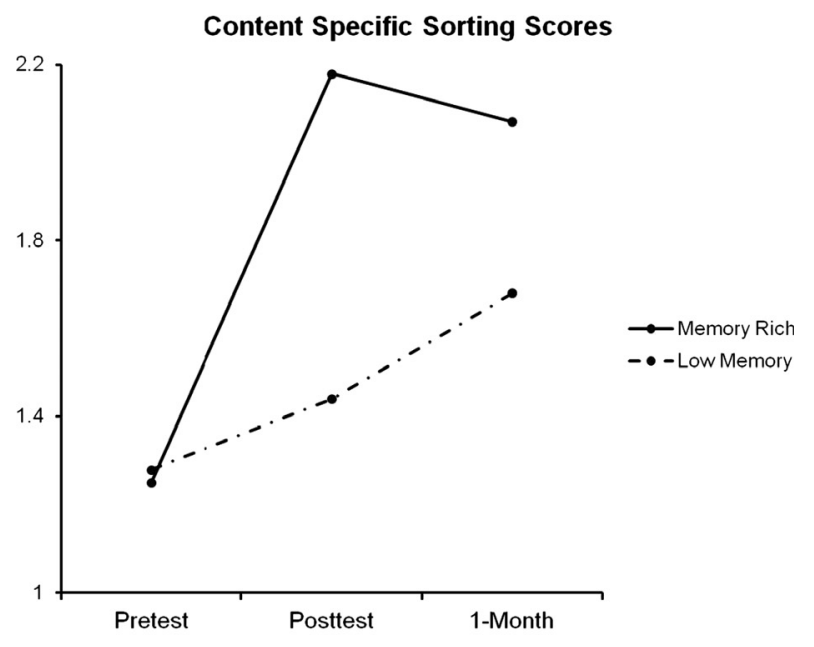

Sorting ARC Scores

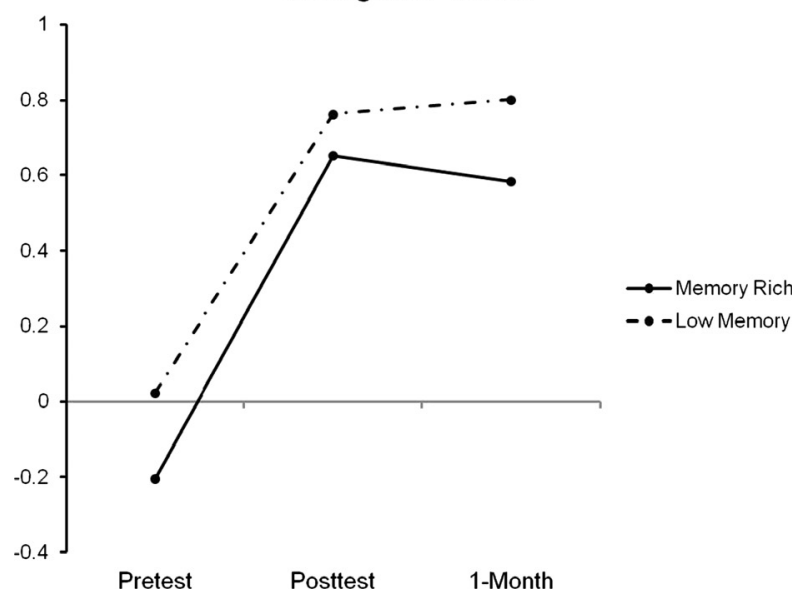

Figure 2. Content-specific sorting and sorting adjusted ratio of clustering scores as a function of teacher instructional style and pretest, posttest, and 1-month follow-up.

the low memory condition. Indeed, the children in the memory rich group made on average at least one semantic or functionally related group with the content-specific stimuli after participating in the experiment. Although nonsignificant, similar trends in performance were seen at the 1-month follow-up.

Although the two instructional groups differed in their deliberate use of newly acquired conceptual knowledge when asked to prepare for remembering in the context of the content-specific sort recall task, it was not clear whether the use of a meaningbased sorting strategy would transfer to taxonomic materials in the free recall with organizational training task (Moely et al., 1992). In this regard, inspection of the bottom panel of Figure 2 indicates that there was no evidence of strategy transfer to this more domain-general sorting task. Specifically, as can be seen when considering the sorting ARC scores that are displayed in the bottom panel of Figure 2, the children in the memory rich instructional condition actually performed below the level of their peers in the low memory group, and this trend was observed at each assessment. Moreover, even though the children's sorting ARC scores increased significantly across the assessment points, $F(2,104)=86.51, p<.01$, the functions of the two groups paralleled each other, and there was no evidence of an Instructional Condition $\times$ Time interaction.

Follow-up analyses revealed that the differences in taxonomic-based sorting between the two conditionsin favor of the children in the low memory condi tion-were significant on the pretest baseline trial. As seen in the bottom panel of Figure 2, the low memory participants sorted on average at a chance level on the baseline trial, but their ARC scores $(M=.02)$ were nonetheless higher than those of children in the memory rich condition $(M=-.20)$, $t(52)=-2.39 p<.05$. In contrast, only two children in the memory rich condition engaged in limited sorting at the initial assessment, whereas five of the participants in the low memory group sorted all of the cards into the appropriate taxonomic groups at the baseline trial before being trained to do so. As can also be seen in Figure 2, children in both instructional conditions responded to the training in categorical sorting that was provided in the free recall with organizational training task, and, as such, increased their meaning-based grouping of the taxonomic materials. Nonetheless, the groups did not differ significantly in their sorting on the posttest and 1-month follow-up trials, although the ARC scores of the children in the low memory condition again exceeded those of their peers in the memory rich condition.

\section{Discussion}

In an attempt to understand the impact of the classroom context on children's developing memory skills, this study was designed to manipulate experimentally the memory-relevant language used by teachers during instruction. Combined with the findings from longitudinal research (e.g., Coffman et al., 2008) that identified associations between naturally occurring differences in teachers' mnemonic style and children's memory performance, the results obtained here have both basic and applied implications. On the one hand, the findings contribute to an understanding of the social 
factors-including those that occur in the form of classroom instruction that impact the development of children's memory-and, on the other hand, they inform applied efforts to develop instructional practice that can influence children's learning in the classroom setting. In addition, by contrasting children's strategic efforts when they are asked to remember items that are linked to the content presented during the Things That Move instructional unit as well as taxonomic materials, it may be possible to make inferences regarding the mechanism by which a memory rich instructional style may impact children's independent strategy use.

\section{The Instructional Manipulation}

Before examining children's outcomes, it was of critical importance to ensure that the teachers were in fact able to make use of the two contrasting styles of instructional language when they taught the Things That Move material. An examination of the coded videotaped lessons revealed that efforts to train the teachers in the use of memory rich and low memory modes of instruction were very successful. Indeed, even though the teachers were asked to conduct the series of lessons twice, once in each of the two contrasting styles, they were able to do so, and they made use of the targeted techniques in their teaching at rates comparable to those observed previously among first-grade teachers (Coffman et al., 2008). Importantly, the level of fidelity exhibited by the teachers reflected their internalization of the basic principles of the two styles of instruction. Thus, not only could they adhere to the lesson scripts in their formal instruction, but they could also engage with the children in one-on-one conversations in ways that reflected the mnemonic style with which they were teaching. Moreover, consistent with the goals of the experimental manipulation, the greatest differences in the observed language of the teachers were found in their provision of metacognitively rich information, their use of metacognitive questions, and in the joint occurrence of memory demands and cognitive structuring and instructional activities.

\section{The Impact of Instruction on Children's Performance}

The findings reveal the specific impact of teachers' use of memory-relevant language on children's growing knowledge of strategies for problem solving within the context of the activities related to the Things That Move content, as well as their ability to apply their newly acquired knowledge in the service of a mean- ing-based organizational strategy. More specifically, even though children who were exposed to both instructional styles acquired facts and strategies concerning Things That Move-as evidenced by the improvement from pretest through posttest and the delayed assessment-clear differences between the groups were seen in terms of their strategic knowledge. Thus, low memory instruction benefited the students' knowledge of facts but not their acquisition of strategies, whereas memory rich instruction appears to impact the acquisition of both of these types of knowledge. Given the strong metacognitive component to memory rich instruction, it seems that the provision of metacognitive information leads children to develop an increased understanding of building strategies with the Things That Move materials.

How might this increased understanding of strategies within the instructional unit be important for children's performance on tasks that involve remembering content-related information? Turning to the children's use of meaning-based sorting strategies with the Things That Move materials, performance also varied as a function of instructional condition. To illustrate, even though the participants initially exhibited relatively unsophisticated sorting patterns on the content-specific sort recall task, after learning about the content (i.e., simple machines and Legos) over the course of the 10-lesson unit, the children in both groups were better able to sort the content-related materials into groups to support remembering. However, as evidenced by their sorting patterns after instruction, the children who experienced the memory rich instructional unit outperformed their peers in the low memory condition, although the effect is reduced at the delayed assessment because of an unexpected improvement in the sorting of the children in the low memory condition.

As can be seen, not only did exposure to instruction that was presented with metacognitively rich language facilitate the acquisition of content-based problem-solving strategies, it also enabled the children to apply what they had learned about the Things That Move materials to form meaning-based groups in the service of a memory goal. However, in contrast to the influence of instructional condition on the children's performance on the contentspecific sort recall task, group differences were not observed on the free recall with organizational training task with taxonomic materials. Indeed, even though the children's strategic sorting on this task was comparable to that found in previous investigations involving children of the same age (e.g., Grammer et al., 2010), no effect of instruction 
on the use of strategic sorting with familiar items was identified. This contrasting set of findings is interesting because although the materials presented in these two tasks differed markedly in terms of underlying structure, in both cases the demands of each task-requiring children to make use of their knowledge of the semantic relations among the items to create groups-were the same.

\section{The Role of Instruction in Children's Strategy Development}

The impact of instruction on the children's performance within the content-specific sort recall task seems likely to stem directly from the differences in the language with which the Things That Move materials were presented to the two groups. For example, although there was no direct instruction in the use of strategic sorting in the memory rich conditions, the lessons nonetheless involved strategy suggestions and requests for the children to explain their building techniques, with the result being an increased understanding of how the Lego pieces might work together. In addition, the teachers explicitly drew connections between the materials through their use of language that emphasized cognitive structuring activities. Alternatively, the scripted lessons presented to the children in the low memory condition emphasized imparting novel pieces of information, such as the names of the Lego pieces, through the provision of general information and probes of the children's developing knowledge base. The children's performance on the content-specific sort recall task seems to reflect these differences in instruction, with interitem associations among the Lego pieces being used more readily in the service of a memory goal by the children who received memory rich instruction, in contrast to those in the low memory group who instead tended to group on the basis of surface features such as color or shape.

What characteristics of memory rich instruction might be driving these group differences in strategic understanding and the application of newly acquired knowledge? It seems clear that the performance of the children in the memory rich condition did not result from direct instruction on the use of these strategies, but instead from more subtle aspects of the way in which information in lessons was presented. Although memory rich instruction included extensive amounts of strategy-related talk, the direct provision of strategy suggestions by the teacher to the children was relatively rare, occurring only $10 \%$ of the time. Furthermore, these strategy suggestions were not always directly made with regard to the specifics of building structures and vehicles with the Legos, but also to more general ways in which the children might think about other aspects of the material presented. Importantly, the majority of the metacognitively relevant information included in the memory rich lessons was delivered in the form of metacognitive questions related to the Lego content. By asking these types of questions, the teachers implicitly provided opportunities for the children to learn about the use of strategies for both building and thinking about the instructional content.

\section{Linking the Experimental Manipulation to Instruction in School}

In relating the present findings to the longitudinal research that set the stage for this experiment (Coffman et al., 2008), it seems likely that some teachers foster the development of children's sophisticated approaches to remembering not by providing direct instruction in memory strategies but rather by the language that they use in the context of lessons in instructional domains such as mathematics and language arts. In turn, children may first gain strategic understanding and apply this knowledge within specific areas of study, analogous to what was seen in here with regard to the children's performance with the Things That Move materials. Indeed, it seems possible that over the course of a school year, these skills may generalize such that the sophisticated strategies that are first evidenced in specific content domains come to be applied in more generally in tasks that require remembering. As such, consistent with the previous longitudinal observations (Coffman et al., 2008), long-term exposure to elevated levels of memory-relevant language, may facilitate children's general memory skills.

It should be noted that there is a clear boundary condition associated with exposing children to high mnemonic language during a 2-week instructional unit. Although the children given memory rich instruction outperformed their peers in the low memory condition in their performance on the content-specific sort recall task, there were no group differences in the children's strategic sorting of familiar semantically related items in the free recall with organizational training task. This is particularly interesting in that such differences as a function of high versus low mnemonic instruction were observed in Coffman et al.'s (2008) longitudinal study. However, to understand the failure to obtain such an effect in the present experiment, it is necessary to consider a 
number of factors, including the strength of the present manipulation and the initial levels of performance of the children in the two groups.

Consider first, the strength of the instructional manipulation. In contrast to their day-to-day experiences in the classroom setting, the children in this study were exposed to the material for a relatively short period of time. Indeed, the first graders whose teachers were observed by Coffman et al. (2008) had extensive exposure to the instructional styles of their teachers that were clearly not replicated in a 10-day experimental project. As such, the amount of instruction offered the children in the present experiment was a small fraction of the "dose" of memory-relevant language that was received by the first graders studied by Coffman et al. It is also the case that the manipulation in the present experiment was carried out in the context of a single instructional unit, whereas in the content of ongoing elementary school instruction, children are exposed to their teachers' mnemonic styles in multiple domains of the curriculum. Furthermore, it is possible that participants' classroom teachers might have been modeling daily a style of instruction that was not consistent with that to which the children were exposed in the present experiment, further diluting the strength of the intended manipulation. It is also possible that the children's everyday exposure to the mnemonic style of their teachers contributed to their initial strategic skills, but whatever the cause of these differences at the outset of the experiment, their presence increased the difficulty of obtaining a generalized effect of the present instructional manipulation.

In sum, the results reported here provide insight into the acquisition of memory skills in school-aged children. Although age-related changes in these abilities have been well documented in previous research, the current findings build on this basic understanding of the development of memory and extend it to include information regarding specific contextual factors that likely impact the development of these skills. This investigation represents an initial effort to explore experimentally the impact of teacher instructional style and is the first of a series of projects designed to inform future classroom-based interventions in teachers' provision of memory-relevant language in the classroom setting. Additional investigations, involving instructional content from a variety of domains (e.g., mathematics and language arts) that are carried out during the regular school day over greater periods of time, as opposed to the after school setting, are needed to explore further the relation between instruction and children's outcomes. Although further research is still needed to better understand the underlying mechanisms and broader impact of instruction on children's memory development, the success-within the context of materials drawn from the domain of instruction - of the manipulation carried out here provides further evidence for the importance of memory-relevant language when teaching children.

\section{References}

Bjorklund, D. F., Ornstein, P. A., \& Haig, J. R. (1977). Developmental differences in organization and recall: Training in the use of organizational techniques. Developmental Psychology, 13, 175-183. doi:10.1037/0012-1649. 13.3.175

Coffman, J. L., Ornstein, P. A., McCall, L. E., \& Curran, P. J. (2008). Linking teachers' memory-relevant language and the development of children's memory skills. Developmental Psychology, 44, 1640-1654. doi: 10.1037 /a0013859

Craik, F. I. M., \& Lockhart, R. S. (1972). Levels of processing: A framework for memory research. Journal of Verbal Learning and Verbal Behavior, 11, 671-684. doi: 10.1016/S0022-5371(72)80001-X

Crosnoe, R., Morrison, F., Burchinal, M., Pianta, R., Keating, D., Friedman, S., et al. (2010). Instruction, teacherstudent relations, and math achievement trajectories in elementary school. Journal of Educational Psychology, 102, 407-417. doi:10.1037/a0017762

Dunn, L. M., \& Dunn, D. M. (2007). Peabody Picture Vocabulary Test. (4th ed.). Minneapolis, MN: Pearson.

Grammer, J. K., Coffman, J. L., Sydney, P. G., \& Ornstein, P. A. (2013). Linking teacher instruction and student achievement in mathematics: The role of teacher language. Manuscript submitted for publication.

Grammer, J. K., Purtell, K. M., Coffman, J. L., \& Ornstein, P. A. (2011). Relations between children's metamemory and strategic performance: Time-varying covariates in early elementary school. Journal of Experimental Child Psychology, 108, 139-155. doi:10.1016/j.jecp. 2010.08.001

Haden, C. A., Ornstein, P. A., Eckerman, C. O., \& Didow, S. M. (2001). Mother-child conversational interactions as events unfold: Linkages to subsequent remembering. Child Development, 72, 1016-1031. doi:10.1111/14678624.00332

McCarthy, D. A. (1972). Manual for the McCarthy Scales of Children's Abilities. New York: Psychological Corporation.

Moely, B. E., Hart, S. S., Leal, L., Santulli, K. A., Rao, N., Johnson, T., et al. (1992). The teacher's role in facilitating memory and study strategy development in the elementary school classroom. Child Development, 63, 653-672. doi:10.2307/1131353

Morrison, F. J., Smith, L., \& Dow-Ehrensberger, M. (1995). Education and cognitive development: A natural experiment. Developmental Psychology, 31, 789-799. doi:10.1037/0012-1649.31.5.789 
Ornstein, P. A., Baker-Ward, L., \& Naus, M. J. (1988). The development of mnemonic skill. In F. E. Weinert \& M. Perlmutter (Eds.), Memory development: Universal changes and individual differences (pp. 31-50). Hillsdale, NJ: Erlbaum.

Ornstein, P. A., Coffman, J. L., Grammer, J. K., San Souci, P. P., \& McCall, L. E. (2010). Linking the classroom context and the development of children's memory skills. In J. Meece \& J. Eccles (Eds.), Handbook of research on schools, schooling, and human development (pp. 42-59). New York: Routledge.

Ornstein, P. A., \& Corsale, K. (1979). Process and structure in children's memory. In G. Whitehurst \& B. J. Zimmerman (Eds.), The functions of language and cognition (pp. 199-228). New York: Academic Press.

Ornstein, P. A., Grammer, J. K., \& Coffman, J. L. (2010). Teachers' "mnemonic style" and the development of skilled memory. In H. S. Waters \& W. Schneider (Eds.), Metacognition, strategy use, and instruction (pp. 33-53). New York: Guilford.

Ornstein, P. A., \& Haden, C. A. (2001). Memory development or the development of memory? Current Directions in Psychological Science, 10, 202-205. doi:10.1111/ 1467-8721.00149

Ornstein, P. A., Haden, C. A., \& Elischberger, H. B. (2006). Children's memory development: Remembering the past and preparing for the future. In E. Bialystok \& F. I. M. Craik (Eds.), Lifespan cognition: Mechanisms of change (pp. 143-161). New York: Oxford University Press.

Ornstein, P. A., Haden, C. A., \& San Souci, P. (2010). The development of skilled remembering in children. In J. H. Byrne (Editor-in-Chief) and H. Roediger III (Vol. Ed.), Learning and memory: A comprehensive reference: Vol. 4. Cognitive psychology of memory. Oxford, UK: Elsevier.
Pressley, M., \& Hilden, K. (2006). Cognitive strategies. In D. Kuhn \& R. Siegler (Eds.), Handbook of child psychology: Vol. 2. Cognition, perception, and language (6th ed., pp. 511-556). Hoboken, NJ: Wiley.

Reese, E., Haden, C. A., \& Fivush, R. (1993). Mother-child conversations about the past: Relationships of style and memory over time. Cognitive Development, 8, 403-430. doi:10.1016/S0885-2014(05)80002-4

Roenker, D., Thompson, C., \& Brown, S. (1971). Comparison of measures for the estimation of clustering in free recall. Psychological Bulletin, 76, 45-48. doi:10.1037/ h0031355

Rogoff, B. (1981). Schooling and the development of cognitive skills. In H. C. Triandis \& A. Heron (Eds.), Handbook of cross-cultural psychology (Vol. 4, pp. 233-294). Boston: Allyn \& Bacon.

Schlagmüller, M., \& Schneider, W. (2002). The development of organizational strategies in children: Evidence from a microgenetic longitudinal study. Journal of Experimental Child Psychology, 81, 298-319. doi:10.1006/ jecp. 2002.2655

Schneider, W., \& Pressley, M. (1997). Memory development between 2 and 20. New York: Springer-Verlag.

Sharp, D. W., Cole, M., \& Lave, C. (1979). Education and cognitive development: The evidence from experimental research. Monographs of the Society for Research in Child Development, 44(1-2, Serial No. 178). doi:10.2307/ 3181586

Wagner, D. A. (1978). Memories of Morocco: The influence of age, schooling, and environment on memory. Cognitive Development, 45, 389-396. doi:10.1016/00100285(78)90017-8 